\title{
Characteristics of Farmers of Water Sharing Groups (WSGs) in Ananthapur District of Andhra Pradesh: A Case of Eight Villages
}

\author{
Sanjay Kumar Gupta*, Bhagirath Das and D.U.M. Rao
}

Division of Agricultural Extension, ICAR-Indian Agricultural Research Institute, New Delhi-110012, India

*Corresponding author

\begin{tabular}{|l|}
\hline Ke y w o r d s \\
Farmers, \\
Water sharing \\
groups, Ananthapur \\
District
\end{tabular}

\begin{abstract}
A B S T R A C T
More than $60 \%$ of our population is directly dependent on agriculture for its sustenance. Water is the backbone of the agricultural economy. Rural development is directly related to control over water resources. Access to water is, therefore, the key to sustainable rural livelihoods. It has been observed empirically that the economic status of farmers owning water resources is better than that of those lacking control over such resources. Our rural scenario is marked by inequitable access to water resources, which has resulted in unequal development. The implications of unequal access to water in areas facing scarcity of water are wider. Efficient management of water resources is vital in such areas. Numerous attempts have been made in the recent past to address concerns of equity alongside focusing on groundwater management. The groundwater situation in the villages at the time of the launch of the WSGs was highly discouraging. Water was available at depths of more than 400 feet and rainfall levels were very low. At the same time, awareness on groundwater management was poor among farmers and they had drilled bore wells indiscriminately, which had compounded the problem. Soon as it had launched the water sharing groups, the organisation undertook a participatory exercise to map availability and usage of water resources in the villages. The outcomes were shared with the farmers and they were oriented on various aspects of groundwater management. The members were given regular inputs on issues such as groundwater management, Water Budgeting, Crop Planning and monitoring water in bore wells and groundwater levels. Brainstorming sessions were also held to evolve a set of Social Regulation norms to guide the usage of scarce water resources. The major findings were: Among the sample of the farmer respondents, only 20 for users owned bore wells and shared with 100 farmers who did not own any bore wells. Water sharing has been accepted and farmers have formed and managing the water sharing institutions in villages.
\end{abstract}

\section{Introduction}

Ground water depletion and drying up of open and deep bore water sources is adversely affecting access to safe water for drinking and water for agriculture in many areas in India, more specifically in villages of Andhra Pradesh. Recurring droughts worsened the prevailing water scarcity, jeopardizing the right to water of women and poor living on 
the periphery of these WSGs (Bhasker Tripathi, 2018).

Dryland farmer faced with an uncertainty of declining water table, drying up of the aquifer in times of a drought year when rains fail to recharge the water aquifer and raise water table. Yet he is not worried, because under the social regulation programme (SRP), water sharing is now made possible. Social regulation is an innovative concept in sharing water among dryland farmers. They were able to provide life-saving irrigation to their groundnut crop and could reap in a better harvest. Their ability to come together and adhere to the agreed upon norms was again the crucial factor for their success. Major crops grown are groundnut and red gram. In the citrus gardens, crops like groundnut, sunflower and vegetables are grown in the inter spaces. Since these are all drylands, farmers resort to mixed cropping of groundnut + red gram + castor, cowpea + green gram and Jowar + cowpea (Malgatti, 2008).

A WSGs was developed by mutual consent of the farmers of the village. The farmers whose borewells are filled with water, they can share their water with neighbouring farmers provided they adhere to some five conditions laid down by the group of farmers. These conditions were: The participants in the social regulation programme (SRP) should not dip up any new borewells in their fields (Reddy $e t$ al., 2012). Research Unit for Livelihoods and Natural Resources, Centre for Economic and Social Studies. They need to share water available in the current live borewells, No one should grow paddy, which requires more water. All the participating farmers have to grow only an irrigated dry crop, All the farmers have to help collect the rain water through water harvesting systems and enhance the recharging of the dead borewells and Everyone has to adopt micro-irrigation systems like drip and sprinkler irrigation systems, for which subsidies (50 percent) and financial help (25 percent) from local NGO would be made available, All the participating farmers of SRP need invariably practice NPM methods and practices (CSA, 2018). Once the farmers have agreed upon these five conditions, they have strictly followed them and they were able to get a good crop of groundnut and no one reported any crop losses due to lack of water. Water was shared among the farmers without any troubles or fights. Since new borewells were not dug up, and since water was not wasted, and rain water was harvested properly by all farmers, recharging of lower aquifers was made possible and they were able to get water throughout the crop season. All the villagers were happy for being able to come together and solve their water scarcity problems amicable through collective action and social regulation.

Water Sharing Norms to be followed by the society are pooling up of bore wells through a common pipeline network for sharing Water to be shared among all irrespective of having the ownership of bore well. Crop plans based on availability of water in agreement with members, Reduction of area under paddy, sharing the water to protect the kharif crop of non-bore well farmers. Ensuring the acreage of bore well owner and creating general fund for maintenance of pipeline, repairs, etc. (WASSON, 2018).

\section{Materials and Methods}

The study is was conducted in dryland agroecosystem of Andhra Pradesh. District Ananthapur is purposively selected as large number of farmers is adopting water sharing practices for managing crops water dryland system. A pilot study was conducted before the actual start of research work to check the availability and time taken by the farmers in 
this areas (Billé, 2010). Three Mandals was selected from each district purposively. From these Mandals eight villages were selected randomly. Both the purposive and random sampling was used for selection of respondents. From each village one WSGs selected. Thus total sample of farmers for the study hundred twenty. The collection of data was done by developing a schedule supplemented with in-depth informal discussions, data was collected from the respondents by using personal interview method and focused group discussion with the help of structured and semi-structured interview schedules. The collected data was tabulated, processed and analyzed by using appropriate descriptive and inferential statistical tools. Data collected were from 120 farmers analysed with the help of SPSS 20.0 and Excel Stat software to draw valid conclusion.

\section{Results and Discussion}

All the respondents of this study are dryland farmers and members of water sharing groups. However, they may vary in their socio-personal characteristics. Hence, the socio-personal, socio-economic and sociopsychological characteristics of the respondents are presented here.

\section{Membership in water sharing groups}

To begin with, it has been found that all the respondent farmers were members of water sharing associations and their distribution across the villages is given in Table 1 below. As can be seen from the results, from among three mandals, eight water sharing societies were found, one in each village. Interesting fact was that from among the 120 farmers, only 20 farmers owned bore well and 100 farmer respondents did not own any bore wells.
This shows that the all the farmers came together to form water sharing groups and thereby get mutual benefits. Twenty bore well owning farmers have vowed to provide protective irrigation to all 100 farmers when rains may fail and crops are in dire need of a live saving irrigation.

Age

The age of the respondents was recorded in completed years and the data were analysed and the results are presented in Table 2.

It can be seen from the results in the Table 2, the mean age of farmer respondents was 47.44 years. The standard deviation was 1.17 ; indicating the consistency of respondents on their age. The frequency distribution appears to be skewed towards the old age of respondents.

About 41.64 percent of respondents were older and the 39.16 percent were middle aged. The mean was also representing middle aged respondents. Very few were young (19.2 percent) farmers.

\section{Sex}

Sex of respondents was categorized on nominal level as male and female (Table 6). Although only 6.7 percent of the respondents were women members, in general most of the women were found to take active role in water sharing group's meetings and activities.

\section{Educational status}

Formal education plays a significant role in comprehension of the basic principles involved in sustainable agriculture. Here the educational status of farmer respondents was recorded and analysed. The results are presented in Table 4. 
As can be seen from the results, 35.0 percent of the farmer respondents were educated up to primary level, while nearly 26 percent completed high school education. And only10 percent studied beyond. About 28 percent farmers were illiterates.

\section{Family type}

The family type of respondents was categorized on nominal level as nuclear and joint family. The results are presented in Table 5. As can be seen from the results about 63 percent of farmer respondents lived in joint families. This is a normal feature in dryland areas, where in large number of family labour is used in cultivating crops. So here too, joint families provided family labour.

\section{Family size}

Family size was measured in terms of number of people living in the family. The results are given in Table 6. As evident from the results, nearly 72 percent of farmer respondents lived in medium families of 4 t0 6 members.

\section{Farming experience}

Experience in farming was recorded in total number of years that the farmer was practicing farming as a vocation. The farmers were categorized and their frequency distribution is presented in Table 7.

As can be seen from the results in the Table 7, the frequency distribution appears to be following normal distribution. About 35 percent of the farmers had 20-30 years of farming experience and 31.7 percent had $30-40$ years of farming experience.

The result that about 77 percent farmers having more than 20 years of farming experience can be seen as beneficial to the water sharing groups because their vast experience would guide the group's functioning effectively.

\section{Irrigated land}

The data on land holdings were analysed and the results are presented in Table 8 . As can be seen from the results, about 60 percent were small farmers. Nearly 11 percent were marginal farmers possessing irrigated land of less than one hectare. Another 27.6 percent were semi-medium farmers possessing 2-4 hectares of irrigated drylands. Only 10 percent were medium farmers.

\section{Dryland}

The dryland owned and cultivated has also been recorded and the data were analysed to know the dryland owned as well as cultivated by farmers. The results are given in Table 9. As can be seen from the results, about 56.7 percent farmers were small, with land possession of 1 - 2 ha. About 33 percent were semi-medium farmers, with $2-3$ hectares of dryland cultivated as only rainfed. About 56 percent of the respondents were small farmers possessing 1-2 hectares of rainfed drylands. About 90 percent of them were found to cultivate crops in drylands only at the mercy of rains.

\section{Orchard land}

The orchard land owned was recorded and analysed to know the ownership of orchard land by the farmers. The results are given in Table 10.

About 89 percent of farmer respondents owned orchard land of less than one hectare. Orchards with mango trees, although small, were owned by all the farmers.

\section{Total annual income}

It was measured in the actual terms as income in rupees per year. The sources of income were field crops: ground nut, sorghum, pigeon pea, tomatoes, etc. Most of the farmers get 
considerable income from livestock including cows, goats, sheep and poultry. The results are given in Table 11, As can be seen from the results in the Table 11, mean income of farmer respondents was Rs.84750 rupees and the standard deviation was 35490, which indicates wide variation in the incomes of these farmer respondents. In fact, the incomes ranged from as low as Rs. 30,000 to as high as Rs.3, 60,000 per annum.

About 38 percent of farmers were earning annual incomes between Rs. 51,000 and Rs. 70,000, while nearly 26 percent were earning incomes between Rs. 71,000 and Rs. 90,000. Thus nearly 72 percent of these farmers were earning less than one lakh rupees per annum. Only 27 percent of them were earning more than a lakh of rupees as annual income.

\section{Frequency of Contact with Personal Localite Channels}

The frequency of contact with various localite channels (neighbours, friends and relatives and local leaders) was recorded using a schedule and the data were analysed and the results are given in Table 12.

It can be seen from the results, the neighbours, friends and relatives were most sought after personal localite channels of communication. About 86 percent of respondents often contacted neighbours, while 34 percent of them contacted neighbours most often for communicating purposes. With respect to contacting friends and relatives, about 91 percent of respondents contacted them often.

Only 25 percent of the farmer respondents contacted sometimes or often with local opinion leaders. Thus neighbours, friends and relatives were the personal localite channels of contact often preferred by the farmers

\section{Frequency of contact with cosmopolite channels}

The frequency of contact with various cosmopolite communication channels was recorded using a schedule and the data were analysed and the results are given in Table 13.

Among various cosmopolite channels, farmer respondents were found to contact 'often' the A.D.O., B.D.O., mostly for purpose of getting approvals of the water sharing group's plans and project works for subsidy. V.L.W., officials from cooperatives, experts from research organisations, K.V.K., and ATMA were never met by most of the respondents. However, staff of NGO and community resource persons (CRPs) were contacted 'most often'. The reason for contacting more often these local people was these two sets of persons were the real grassroots level personnel who had persuaded them to form into water sharing groups. In addition, these people have appraised the farmers of the current critical scenario of water shortages, mistakes done earlier and taught them all the water management innovations.

\section{Frequency of Contact with Mass Communication Channels}

The frequency of use of various mass communication sources was recorded using a schedule and the data were analysed and the results are given in Table 14.

As evident from the results on contact with mass communication channels, majority of the farmers were found to be never reading newspapers, not listening to radio and not reading any pamphlets or bulletins. However, they were found to be watching television 'most often'. Some of them were found to be visiting exhibitions and kisanmelas. However, with respect to group meetings at village and Mandal levels, majority of farmer respondents 
were found to be attending 'most often' as the meetings were dealt with water related issues, problems and solutions.

\section{Socio-psychological Characteristics of Farmer Respondents}

Three variables under this category were chosen for this study: goal commitment, social capital and respondent's adherence to social norms.

\section{Goal commitment}

Goal commitment is the most important socio-psychological variable of the study. In this study, commitment of the farmer respondents towards the goal of water sharing groups was studied using a scale developed by Singh (1998). The scale consisted of 6 questions and the possible answers were scored on a three-point continuum of agreement or disagreement, with scores of 2, 1 , and 0 . The results are given in Table 15 .

As can be seen from the results in the Table 15, mean goal commitment of farmer respondents was 6.24. The standard deviation was 1.365; which indicates consistency among the respondents on their goal commitment. The frequency distribution appears to be slightly skewed towards low goal commitment scores of the group. About 42 percent of respondents possessed low level of goal commitment, while 34 percent of them possessed high level of goal commitment.

\section{Social capital}

"Social capital is founded upon shared beliefs, norms and values depending upon trust existing between the actors involved" For measuring social capital, three components i.e., faith, norms and social interactions among the members of a group. This was measured using a schedule developed for the study. The results of data analysis are given in (Sharma Arun.2005) Table 16.

It can be seen from the results in the Table, mean social capital of farmer respondents was 66.69. The standard deviation was 6.105 indicating wide variation (from 53 to 83) among the respondents on their social capital scores. The frequency distribution appears to fallow normal distribution, although slightly skewed towards higher scores. About 69 percent of respondents possessed moderate levels of social capital. About 16 percent of them were having high level of social capital, while another 14 percent of them had low levels of social capital.

\section{Social Norms}

The water sharing groups were formed with an understanding that all the member farmers would comply with the norms set up by the water sharing group. Here the compliance of respondents with the social norms was measured. Compliance to social norms refers to the degree to which a farmer adheres to group-held beliefs and values and the degree to which his or her community or society approves his or her behaviour.

A total of 9 statements were developed to measure the given variable in a five-point continuum of agreement or disagreement. The maximum possible score was 45 and the minimum was 9 . The data were analysed and the results are given in Table 17.

It can be seen from the results that mean score of adherence to social norms of farmer respondents was 27.73. The standard deviation was 1.998, which indicates consistency among the respondents on their degree of adherence to social norms. The frequency distribution appears to be slightly skewed towards the low social norms category of respondents. 
About 69 percent of respondents were moderately adhering to social norms. About 20 percent farmers' level of adherence to social norms was high. However, about 10 percent were found to be low on adherence to social norms.

Table.1 Distribution of respondents from different selected Mandals, villages and water sharing groups in Ananthapur district

\begin{tabular}{|l|l|c|c|c|}
\hline $\begin{array}{c}\text { Villages in Three } \\
\text { Mandals of } \\
\text { Ananthapur }\end{array}$ & \multicolumn{1}{|c|}{ Name of Water Sharing Group } & $\begin{array}{c}\text { Bore } \\
\text { well } \\
\text { Owners }\end{array}$ & $\begin{array}{c}\text { Non- } \\
\text { Owners } \\
\text { of Bore } \\
\text { well }\end{array}$ & $\begin{array}{c}\text { Tota } \\
\text { I }\end{array}$ \\
\hline Gandlapenta Mandal & & 4 & 12 & $\mathbf{1 6}$ \\
\hline 1. Karnamwaripalli & SrinivasaUmmadiNeetiYajamanyaSangham & 2 & 10 & $\mathbf{1 2}$ \\
\hline 2. Kumarwandlapalli & KoluguntiUmmadiNeetiYajamanyaSangham & 2 & 9 & $\mathbf{1 1}$ \\
\hline 3. Narasappagaripalli & MallikaadaUmmadiNeetiYajamanyaSangham & 4 & 19 & $\mathbf{2 3}$ \\
\hline 4. Kamathampalli & KhadriSusthiraBhugarbhajalaYaajamaanyaSangham & & & \\
\hline Kadiri Mandal & Ganga BhawaniUmmadiNeetiYajamanyaSangham & 2 & 12 & $\mathbf{1 4}$ \\
\hline 1. Patnam & & 2 & 14 & $\mathbf{1 6}$ \\
\hline Nallacheruvu Mandal & ChinnamarapuUmmadiNeetiYajamanyaSangham & 2 & 16 & $\mathbf{1 8}$ \\
\hline 1. Padllewaldlapalli & UdumbandaUmmadiNeetiYajamanyaSangham & 2 & 8 & $\mathbf{1 0}$ \\
\hline 2. Bodnepalli & TakkillagaddaRaithuSangham & 20 & 100 & 120 \\
\hline 3. Devireddypalli & Eight Societies & & \\
\hline Total & & & 2 & \\
\hline
\end{tabular}

Table.2 Distribution of farmer respondents on their age

\begin{tabular}{|l|c|c|}
\hline Age of Respondents & \multicolumn{2}{|c|}{ N=120 } \\
\hline Mean & \multicolumn{2}{|c|}{47.44} \\
Standard Deviation & \multicolumn{2}{|c|}{1.17} \\
Range & \multicolumn{2}{|c|}{$26-75$} \\
\hline Frequency Distribution & Frequency & Percent \\
\hline Young (< 35 years) & 23 & 19.20 \\
Middle aged Between 36 \& 50 & 47 & 39.16 \\
years & 50 & 41.64 \\
Old (>51 years) & & \\
\hline Total & $\mathbf{1 2 0}$ & $\mathbf{1 0 0 . 0 0}$ \\
\hline
\end{tabular}

Table.3 Distribution of farmer respondents on sex

\begin{tabular}{|l|c|c|}
\hline Gender & Frequency & Percent \\
\hline Men & 112 & 93.3 \\
\hline Women & 8 & 6.7 \\
\hline Total & 120 & 100.0 \\
\hline
\end{tabular}


Table.4 Distribution of farmer respondents on Educational Status

\begin{tabular}{|l|c|c|c|}
\hline Category & Code & Frequency & Percent \\
\hline Illiterate & 0 & 34 & 28.3 \\
\hline Primary & 1 & 42 & 35.0 \\
\hline High School & 2 & 31 & 25.8 \\
\hline Intermediate & 3 & 2 & 1.7 \\
\hline Degree & 4 & 2 & 1.7 \\
\hline Diploma & 5 & 9 & 7.5 \\
\hline Total & & $\mathbf{1 2 0}$ & $\mathbf{1 0 0 . 0}$ \\
\hline
\end{tabular}

Table.5 Distribution of farmer respondents on family type

\begin{tabular}{|l|c|c|c|}
\hline Family type & Code & Frequency & percent \\
\hline Nuclear & 1 & 44 & 36.66 \\
\hline Joint & 2 & 76 & 63.3 \\
\hline Total & & $\mathbf{1 2 0}$ & $\mathbf{1 0 0 . 0}$ \\
\hline
\end{tabular}

Table.6 Distribution of farmer respondents on family size

\begin{tabular}{|c|l|c|c|c|}
\hline No. & Family Size & Size & Frequency & percent \\
\hline 1 & $<3$ members & Small & 33 & 27.5 \\
\hline 2 & $4-6$ members & Medium & 86 & 71.7 \\
\hline 3 & $>7$ members & Large & 1 & .8 \\
\hline & Total & & $\mathbf{1 2 0}$ & $\mathbf{1 0 0 . 0}$ \\
\hline
\end{tabular}

Table.7 Distribution of farmer respondents on farming experience

\begin{tabular}{|c|c|c|c|c|}
\hline Sl. No. & Experience in cultivation & Code & Frequency & percent \\
\hline 1. & $>10$ year & 1 & 14 & 11.7 \\
\hline 2 & $10-20$ years & 2 & 29 & 11.8 \\
\hline 3 & 20-30 years & 3 & 32 & 35.1 \\
\hline 4 & 30-40 years & 4 & 24 & 31.7 \\
\hline 5 & $>40$ years & 5 & 21 & 10.7 \\
\hline & Total & & $\mathbf{1 2 0}$ & $\mathbf{1 0 0}$ \\
\hline
\end{tabular}

Table.8 Distribution of farmer respondents on irrigated land

\begin{tabular}{|l|l|c|c|c|}
\hline Sl. No. & Farmers' category & Range in ha & Frequency & Percent \\
\hline $\mathbf{1}$ & Marginal farmers & $<1$ & 13 & 10.8 \\
\hline $\mathbf{2}$ & Small farmers & $1-2$ & 72 & 60.0 \\
\hline $\mathbf{3}$ & Semi-medium farmers & $2-4$ & 23 & 27.4 \\
\hline $\mathbf{4}$ & Medium farmers & $>4$ & 12 & 10.0 \\
\hline Total & & & $\mathbf{1 2 0}$ & $\mathbf{1 0 0}$ \\
\hline
\end{tabular}


Table.9 Distribution of farmer respondents on dryland

\begin{tabular}{|l|l|c|c|c|}
\hline Sl. No. & Farmers category & Range in ha & Frequency & Percent \\
\hline $\mathbf{1}$ & Marginal farmers & $<1$ & 7 & 5.8 \\
\hline $\mathbf{2}$ & Small farmers & $1-2$ & 68 & 56.7 \\
\hline $\mathbf{3}$ & Semi-medium farmers & $2-4$ & 41 & 33.3 \\
\hline $\mathbf{4}$ & Medium farmers & $>4$ & 4 & 4.2 \\
\hline Total & & & $\mathbf{1 2 0}$ & $\mathbf{1 0 0}$ \\
\hline
\end{tabular}

Table.10 Distribution of farmer respondents on orchard land

\begin{tabular}{|l|l|c|c|c|}
\hline Sl. no. & Farmers category & Range in ha & Frequency & Percent \\
\hline $\mathbf{1}$ & Marginal farmers & $<1$ & 107 & 89.2 \\
\hline $\mathbf{2}$ & Small farmers & $1-2$ & 9 & 7.5 \\
\hline $\mathbf{3}$ & Semi-medium farmers & $2-4$ & 3 & 2.5 \\
\hline $\mathbf{4}$ & Medium farmers & $>4$ & 1 & .8 \\
\hline Total & & & $\mathbf{1 2 0}$ & $\mathbf{1 0 0}$ \\
\hline
\end{tabular}

Table.11 Distribution of farmer respondents on total annual income

\begin{tabular}{|c|c|c|}
\hline Total income of Respondents (Rs.) & & $\mathrm{N}=120$ \\
\hline Mean & \multicolumn{2}{|c|}{84,750} \\
\hline Standard Deviation & \multicolumn{2}{|c|}{35,490} \\
\hline Range & \multicolumn{2}{|c|}{$30,000-3,60,000$} \\
\hline Frequency Distribution & Frequency & Percent \\
\hline Very low $(\mathbf{3 0 , 0 0 0}-\mathbf{5 0 , 0 0 0 )}$ & 10 & 8.33 \\
\hline Low $(51,000-70,000)$ & 46 & 38.33 \\
\hline Middle (71,000 - 90,000) & 31 & 25.83 \\
\hline High (91000-1,11,000) & 16 & 13.33 \\
\hline $\begin{array}{l}\text { Moderately high }(1,11,000 \text { - } \\
1,30,000)\end{array}$ & 12 & 10.00 \\
\hline Very High >1,31,000) & 5 & 4.17 \\
\hline Total & 120 & 100 \\
\hline
\end{tabular}

Table.12 Distribution of farmer respondents on frequency of contact with personal localite channels

\begin{tabular}{|l|c|c|c|c|}
\hline Personal Localite channels & \multicolumn{4}{|c|}{ Frequency of Contact / Exposure } \\
\cline { 2 - 5 } & Most often & Often & Sometimes & Never \\
\hline 1. Neighbours & 34 & 86 & 0 & 0 \\
\hline 2. Friends / Relatives & $(28.33)$ & $(70.00)$ & & 0 \\
\hline 3. Opinion Leaders & 10 & 110 & 0 & 90 \\
& $(8.33)$ & $(91.67)$ & & $(75.00)$ \\
\hline
\end{tabular}


Table.13 Distribution of farmer respondents on frequency of contact with cosmopolite channels

\begin{tabular}{|l|c|c|c|c|}
\hline \multirow{2}{*}{ Cosmopolite channels } & \multicolumn{3}{|c|}{ Frequency of Contact / Exposure } \\
\cline { 2 - 5 } & Most often & Often & Sometimes & Never \\
\hline 1. V.L.W. & 0 & 2 & 0 & 118 \\
\hline 2. A.D.O & & $(1.6)$ & & $(98.3)$ \\
\hline 3. B.D.O. & 5 & 74 & 27 & 14 \\
& $(4.2)$ & 61.7 & $(22.5)$ & $(11.7)$ \\
\hline 4. Cooperative official & 20 & 66 & 7 & 27 \\
& $(16.7)$ & $(55.0)$ & $(5.8)$ & $(22.5)$ \\
\hline 5. Expert from research & 2 & 6 & 0 & 108 \\
& $(1.7)$ & $(5.0)$ & & $(90.0)$ \\
\hline 6. ATMA & 2 & 6 & 0 & 112 \\
\hline 7. KVK & $(1.7)$ & $(5.0)$ & $(93.3)$ \\
\hline 8. NGO & 0 & 15 & 22 & 83 \\
& & $(12.5)$ & $(18.3)$ & $(69.2)$ \\
\hline 9. Community Resource & 2 & 0 & 29 & 89 \\
Persons & $(1.7)$ & & $(24.2)$ & $(74.2)$ \\
\hline
\end{tabular}

Table.14 Distribution of farmer respondents on frequency of contact with mass communication channels

\begin{tabular}{|l|c|c|c|c|}
\hline \multirow{2}{*}{ Mass Communication Channels } & \multicolumn{4}{|c|}{ Frequency of Contact / Exposure } \\
\cline { 2 - 5 } & $\begin{array}{c}\text { Most often } \\
\mathbf{( 4 )}\end{array}$ & $\begin{array}{c}\text { Often } \\
\text { S. }\end{array}$ & $\begin{array}{c}\text { Sometimes } \\
\text { 1. Newspaper }\end{array}$ & $\begin{array}{c}\text { Never } \\
\text { (2) }\end{array}$ \\
\hline 2. Radio & $(27.5)$ & 5 & 1 & 81 \\
& 0 & 0 & $(0.8)$ & $(67.5)$ \\
\hline 3. T.V. & 62 & 23 & 0 & 119 \\
\hline 4. Pamphlet/Bulletin etc. & $(51.4)$ & $(19.2)$ & & $(29.2)$ \\
\hline 5. Krishi Mela/Exhibitions & 11 & 7 & 29 & 73 \\
\hline 6. Group Meetings & $(9.2)$ & $(5.8)$ & $(24.2)$ & $(60.8)$ \\
\hline & $(16.7)$ & $(35.2)$ & $(1.7)$ & $(47.5)$ \\
\hline
\end{tabular}


Table.15 Distribution of farmer respondents on goal commitment

\begin{tabular}{|l|c|c|}
\hline Goal commitment of Respondents & \multicolumn{2}{|c|}{ N=120 } \\
\hline Mean & \multicolumn{2}{|c|}{1.365} \\
\hline Standard Deviation & \multicolumn{2}{|c|}{$4-8$} \\
\hline Range & Frequency & Percent \\
\hline Frequency Distribution & 51 & 42.5 \\
\hline Low & 28 & 23.7 \\
Medium & 41 & 34.2 \\
\hline High & $\mathbf{1 2 0}$ & $\mathbf{1 0 0 . 0 0}$ \\
\hline Total & & \\
\hline
\end{tabular}

Table.16 Distribution of farmer respondents on social capital

\begin{tabular}{|l|c|c|}
\hline Social capital Respondents & \multicolumn{2}{|c|}{66.69} \\
\hline Mean & \multicolumn{2}{|c|}{6.105} \\
\hline Standard Deviation & \multicolumn{2}{|c|}{$53-83$} \\
\hline Range & Frequency & Percent \\
\hline Frequency Distribution & 1 & 0.8 \\
\hline Very Low & 16 & 13.33 \\
\hline Low & 83 & 69.17 \\
\hline Medium & 11 & 9.18 \\
\hline High & 9 & 7.6 \\
\hline Very High & $\mathbf{1 2 0}$ & $\mathbf{1 0 0 . 0 0}$ \\
\hline Total & & \\
\hline
\end{tabular}

Table.17 Distribution of farmer respondents on Social Norms

\begin{tabular}{|l|c|c|}
\hline Compliance Social Normsof Respondents & \multicolumn{2}{|c|}{ N=120 } \\
\hline Mean & \multicolumn{2}{|c|}{27.73} \\
\hline Standard Deviation & \multicolumn{2}{|c|}{1.998} \\
\hline Range & \multicolumn{2}{|c|}{$24-31$} \\
\hline Frequency Distribution & Frequency & Percent \\
\hline Low & 13 & 10.8 \\
\hline Medium & 83 & 69.16 \\
\hline High & 24 & 20.0 \\
\hline Total & $\mathbf{1 2 0}$ & $\mathbf{1 0 0 . 0 0}$ \\
\hline
\end{tabular}

In conclusion the sample of respondents was dryland farmers and are members of water sharing groups. Out of 120 farmer respondents, 100 did not own any bore well, and only 20 farmers owned bore wells. All the farmers were sharing rain water for growing irrigated crops. About 40 percent of farmers were middle aged and another 40 percent 
were old. Only 25 percent attended high school, while 35 percent could attend only primary school. Another 28 percent of them were illiterate. About 42 percent of farmers were practicing dryland farming for 30-40 years. They have survived many years in drylands and possessed ways of coping with vagaries of monsoon.

About 60 percent of the respondents were small farmers possessing and cultivating 1-2 hectares of irrigated lands. About 56 percent of them were small farmers with rainfed drylands. Almost all of them possessed small orchards with mango tress. The average annual income was Rs. 85000, while 64 percent of them had annual incomes ranging between fifty and ninety thousands of rupees. About 63 percent of them were living in medium sized joint families. Joint family system was one of the key characteristics of farming families in drylands. Large joint families provide a considerable amount of family labour required for dryland farming systems.

With respect to their contact with localite channels, neighbours friends and relatives were often contacted for information. Among the cosmopolite channels, their contact was limited to 'very often' contact with only NGO activists and the community resource persons. With respect to their contact with mass communication channels, television and group meetings were 'often' contacted.

Among the socio-psychological characteristics of farmers, goal commitment of the farmer respondents was at moderate level. Social capital among the water sharing farmers was moderate to high and their adherence to social norms was also at moderate level.

Thus it can be concluded that the characteristics of the farmers appears to be at medium levels on all the socio-personal variables of the study.

\section{References}

Anonymous. 2017. Anantapur farmers leaving agriculture in droves. http://www.thehindu.com/news/nation al/andhra-pradesh/anantapurfarmersleaving-agriculture-in-droves/article 19333276.ece. 27 NOV., 2017.

Billé, R. (2010) "Action without change. On the use and usefulness of pilot experiments in environmental management." S.A.P.I.EN.S. 3 (1).

Bhasker Tripathi. 2018. Bengaluru, Delhi, Chennai and Hyderabad among 21 Cities to Run Out Of Groundwater by 2020. https://www.indiaspend.com/ bengaluru-delhi-chennai-andhyderabad-among-21-cities-to-runout-of-groundwater-by-2020-2020/.

CSA (Center for Sustainable Agriculture.) (2018). Non Pesticidal Management. http://csa-india.org/what-we-do/npm/. $1^{\text {st }}$ Dec., 2018.

Malgatti, M. (2008). Non-Pesticidal Management in Crops: Community Managed Extension, Processes and Impacts (Doctoral dissertation).

Reddy, M. S., Reddy, V. R., and Mohan, R. R. (2012). Institutionalising Groundwater Management: A Tale of Three Participatory Models in Andhra Pradesh. Research Unit for Livelihoods and Natural Resources, Centre for Economic and Social Studies.

WASSON (2018). Participatory groundwater management.

http://www.wassan.org/theme/particip atory-ground-water-management. $\quad 1^{\text {st }}$ Dec., 2018.

Sharma Arun.(2005) "Entrepreneurial value and social capital among the vegetable growers of Solan districts: A critical 


\section{analysis" M.Sc. thesis choudhary bahagitakeghatyatmakpaksh- charansinghmerut university, 2005. \\ Singh, Lakhan (1998). ekadhyan" Ph.D. thesis, ICAR-IARI- NEW DELHI-12. \\ "Doonghatjalagampariyojnameiensaha}

\section{How to cite this article:}

Sanjay Kumar Gupta, Bhagirath Das and Rao, D.U.M 2018. Characteristics of Farmers of Water Sharing Groups (WSGs) in Ananthapur District of Andhra Pradesh: A Case of Eight Villages. Int.J.Curr.Microbiol.App.Sci. 7(12): 2438-2450. doi: https://doi.org/10.20546/ijcmas.2018.712.277 